\title{
Study Abroad and the Boomerang Effect: The End is Only the Beginning
}

\author{
Richard J. Rexeisen \\ University of St. Thomas
}

\section{Introduction}

As research on the effectiveness of study abroad programs continues to evolve, we are beginning to see a gradual shift in focus from "Is study abroad effective?" to "What can we do to improve the quality of the study abroad experience?" (e.g., Pederson, 2010; Shaheen, 2004). We believe that this broadened perspective is a natural consequence of the maturing of assurance of learning programs at institutions of higher education (e.g., AACSB: Eligibility Procedures and Accreditation Standards for Business Accreditation, 2012; Higher Learning Commission (HLC), Criteria for Accreditation, 2012; de Witt, 2010).

Refinements in methodology and baseline effectiveness will of course continue to be an important and ongoing body of work (e.g., Anderson and Lawton, 2011; Braskamp et al. 2009; Rexeisen \& Al-Khatib, 2009; Vande Berg et al., 2009). The current study adds to the current literature by addressing a gap in the existing study abroad outcomes assessment literature by focusing on the question of whether the developmental benefits of study abroad endure over time.

\section{Literature Review}

Many reasons exist about why institutions of higher education are interested in demonstrating the effectiveness of their study abroad programs. The rapid growth of study abroad over the last few decades (National Center for Education Statistics, 2010), in combination with the heightened competition for scarce resources at American universities (Expanding Study Abroad Capacity at U.S. Colleges and Universities, 2009) have certainly contributed to the interest in exploring the effectiveness of international programming. Recently we have also seen growing interest in assessing the longer-term benefits of study abroad to include such outcomes as career benefits (Franklin, 2010; Norris and Gillespie, 2008).

Over the years a variety of dependent measures have been developed and used to assess the effectiveness of study abroad (e.g., Hammer et al., 2003; Kelley \& Meyers, 1995; Niu \& Cooper, 2010; Paige et al., 2003; Savicki et al., 2004; Shealy, 2005; Shimp and Sharma, 1987). For the purposes of this study, 
however, Hammer's (2007) Intercultural Development Inventory (IDI) offers several distinct advantages including: 1) as a practical research consideration the IDI was used in the exploratory study that first identified the possibility of developmental regression that could occur after the conclusion of a study abroad experience, 2) the IDI is an unique measure of cross-cultural sensitivity in that it is both developmental and theoretically grounded (Bennett 1986, 1993). As a consequence, more opportunities exist for testing, development and generalization of results even when non-probability samples are used; a common limitation of study abroad research (Davis and Finney, 2006), 3) If it is the case that study abroad has long-term developmental consequences, then it is important to establish a basis for examining potential learning interventions to address any newly identified concerns. In this regard, Paige (2004) has suggested that the IDI is very useful in the design of intercultural training programs, and 4) multiple validation studies have been published affirming the psychometric properties of IDI (Hammer et al., 2003; Paige et. al., 2003).

Briefly, the IDI measures an individual's cultural development as they progress from having a more self-centered or mono-cultural mindset (represented by Denial/Defense, Reversal and Minimization) toward having more of an other-oriented, pluralistic or multicultural worldview (represented by acceptance, adaptation and integration). Reversal, a scale that is of particular interest in the current study, is essentially the "mirror image" of the denial/ defense orientation by continuing the polarization of differences, or a sense of "us" versus "them." In both the Defense and Reversal stages, a worldview is present that is characterized or dominated by an orientation where "... one's own culture is central to reality" (Bennett, 1993).

Based on Bennett's (1993) Developmental Model of Intercultural Sensitivity (DMIS), the IDI measures a respondent's progress in learning how to process cultural differences in progressively more complex ways (Hammer and Bennett, 2003; Hammer, 2008). Bennett's theory essentially states that with experience an individual can learn more sophisticated strategies for processing cultural differences and thereby become more culturally sensitive (Bennett, 2004).

Bennett's (1993) theory generally holds that when interpreting results you should focus your attention on the earliest stages of development where an individual is experiencing difficulty. Difficulty within this context, as explained in the IDI qualifying seminar, is where a person scores lower than a four on one of the subscales of the IDI. Each of the subscales are scored on a range from one to five where the higher the score, the greater the resolution of that particular stage of development. So for example, if a student is working 
to resolve an issue related to defense or denial then there is considerably less value in commenting on issues related to acceptance or adaptation. This is noteworthy given that previous research using the IDI has found that undergraduate students are typically working to resolve minimization issues (Anderson et al. 2006; Engle et al. 2004; Paige et al. 2004). As a consequence we anticipate limiting our analysis of results to Overall Development, Defense/ Denial, Reversal and Minimization; all elements of a worldview characterized by a dominant mono-cultural mindset. We anticipate that student overall development as measured by the IDI will fall within the 85-114 range which is, by definition, characteristic of the Minimization Stage.

A growing number of pre/post measurement studies are beginning to appear in the literature (e.g., Engle and Engle, 2004, Paige, Cohen and Shively, 2004, Medina-López-Portillo, 2004, Anderson et al., 2006, 2011; Vande Berg et al., 2009) with most but not all of the findings indicating that study abroad has a positive impact on learning outcomes when measured at the conclusion of the study abroad experience. Vande Berg et al. (2009) reporting on a multiyear study of the impact of study abroad on intercultural development and language skills also found that results are moderated by such variables as level of immersion, the presence of a cultural mentor and the length of the study abroad experience. Pederson's (2010) study of students studying abroad for a year, in contrast to the Vande Berg et al. (2009) study, did not find a significant improvement in cross-cultural development as measured by the IDI when compared to non-study abroad students. Pederson (2010) is therefore calling for additional follow-up studies to augment the current pre, post-test assessments that are being reported in the literature.

With few exceptions most evidence also suggests that gender will moderate the impact of study abroad experiences (Medina-López-Portillo, 2004; Rexeisen et. al., 2009; Vande Berg et al., 2009). The current study will, therefore, also continue to evaluate the role that gender plays in moderating the impact of study abroad on student outcomes.

\section{Research Hypotheses}

Based on our review of the study abroad literature and the findings of the author's previous exploratory study, we are proposing the following five hypotheses. Hypothesis one flows from the body of evidence that study abroad will have positive impact on the development of cross-cultural sensitivity as measured by the IDI at the conclusion of the study abroad experience.

Hypothesis 1: A semester long, faculty-led study abroad program conducted in a native language environment (English) will have a positive impact on the development of cross-cultural sensitivity as 
measured at the conclusion of the semester by the IDI instrument.

Hypotheses 2, $3 \& 4$ are based on the results of an exploratory study wherein it was observed that students exhibited regressive tendencies four months after returning home from a study abroad experience. In particular, regression on the IDI Reversal Scale appeared to be the primary contributing cause of the erosion in cross-cultural development. Therefore,

Hypothesis 2: Four months after returning home from a semester long study abroad experience overall cross-cultural development will decline as measured by the IDI.

Hypothesis 3: There will be a decline on the IDI Reversal Scale fourmonths after returning home from a study abroad experience.

Hypothesis 4: There will be no net improvement in overall crosscultural development from pre-departure to four-months after returning home from a study abroad experience.

Hypothesis 5 follows the preponderance of evidence concerning the moderating role of gender on the development of cross-cultural sensitivity. Hypothesis 6, as with $\mathrm{H}_{2}, \mathrm{H}_{3} \& \mathrm{H}_{4}$, is grounded in observations made in an earlier exploratory study.

Hypothesis 5: Gender moderates the impact of study abroad on the development of cross-cultural sensitivity as measured at the beginning and the end of the study abroad experience.

Hypothesis 6: Gender moderates the impact of study abroad on the development of cross-cultural sensitivity between the end of the study abroad experience and on follow-up four months after returning home.

\section{Methodology}

\section{The Subjects}

The subjects in this research are 139 traditional undergraduate students from a medium-sized private Midwestern University in the United States. Data is collected over a three-year period and include pre-, post- and follow-up measures from three independent student cohorts participating in a semesterlong study abroad program in London, England. Each cohort is composed respectively of 46, 47 and 46 students resulting in a total sample size of 139 . The average age in each cohort is 21 years and the sample is composed of $63 \%$ women. The average GPA of the group is 3.46 with a range of 2.7 to 3.9. This is a competitive program and students are selected on the basis of GPA, student essays, letters of recommendation and personal interviews. 


\section{The Study}

Hammer and Bennett's (2002) intercultural development inventory (IDI) was administered four months prior to departure for London, one week prior to departure for the return to the United States and then again fourmonths after the students returned to their home campus. The author of the current study received training and is certified to administer and interpret the results of the IDI by the Intercultural Communication Institute and IDI, LLC (Hammer, 2012).

\section{Results}

As predicted (Table 1), overall cross-cultural sensitivity increased significantly between pre-departure $\left({ }^{-}=88.0\right)$ and the conclusion of the study abroad program $\left(^{-}=92.9 ; \mathrm{p}=.003\right)$. A similar observation can be made of the Reversal Scale where improvement was indicated from pre-departure $\left(^{-}=\right.$ $3.58)$ to the conclusion of the study abroad experience $\left(^{-}=3.83 ; \mathrm{p}=.001\right)$. As a consequence we find support for Hypothesis 1 that a semester-long study abroad experience in a native language environment has a positive impact on the development of cross-cultural sensitivity.

Table 1. Pre/Post IDI Results

\begin{tabular}{|l|l|l|l|l|l|l|l|}
\hline Paired One-tailed t-tests of Pre-test vs. Post-test Results \\
\hline & Pre-test Results & \multicolumn{4}{l|}{ Post-test Results } & \\
\hline IDI scales & Ave. & Range & S.D. & Ave. & Range & S.D. $^{*}$ & p-value \\
\hline $\begin{array}{l}\text { Overall } \\
\text { Development }\end{array}$ & 88.0 & $58-126$ & 14.2 & 92.9 & $64-129$ & 14.1 & 0.003 \\
\hline Defense/Denial & 4.07 & $2.8-5.0$ & 0.55 & 4.10 & $2.6-5.0$ & 0.56 & 0.367 \\
\hline Reversal & 3.58 & $2.1-5.0$ & 0.61 & 3.83 & $2.7-5.0$ & 0.62 & 0.001 \\
\hline Minimization & 2.53 & $1.1-4.0$ & 0.6 & 2.57 & $1.0-4.3$ & 0.67 & 0.310 \\
\hline
\end{tabular}

Also as predicted (Table 2 ), overall cross-cultural sensitivity exhibited a significant decline $\left({ }^{-}=92.9\right.$ versus 89.2$)$ four months after returning home from study abroad $(\mathrm{p}=.021)$. This finding supports Hypothesis 2 . We also find that the decline in overall development is due to a decline in reversal tendencies or a higher propensity to judge other cultures as superior to your own $\left({ }^{-}=3.83\right.$ post measurement versus 3.60 on follow-up; $\left.\mathrm{p}=.002\right)$. This finding supports hypothesis 3 and corroborates a suspected tendency observed in an earlier exploratory study. 
Table 2. Post/Follow-up IDI Results

\begin{tabular}{|l|l|l|l|l|l|l|l|}
\hline \multicolumn{7}{|l|}{ Paired One-tailed t-tests of Post-test vs. Follow-up Results } \\
\hline & Post-test Results & \multicolumn{3}{l|}{ Follow-up Results } & \\
\hline IDI scales & Ave. & Range & S.D. & Ave. & Range & S.D. & p-value \\
\hline $\begin{array}{l}\text { Overall } \\
\text { Development }\end{array}$ & 92.9 & $64-129$ & 14.1 & 89.2 & $59-131.9$ & 14.51 & 0.021 \\
\hline Defense/Denial & 4.10 & $2.6-5.0$ & 0.56 & 3.98 & $2.8-5.0$ & 0.52 & 0.120 \\
\hline Reversal & 3.83 & $2.7-5.0$ & 0.62 & 3.60 & $2.1-5.0$ & 0.65 & 0.002 \\
\hline Minimization & 2.57 & $1.0-4.3$ & 0.67 & 2.61 & $1.1-4.3$ & 0.65 & 0.338 \\
\hline
\end{tabular}

When comparing overall cross-cultural development from pre-departure to four-months after returning home, we find support for hypothesis 4 (Table 3 ). The initial improvement in overall development observed at the end of the study abroad experience (Table 1 ) is no longer evident four-months after returning home $\left(^{-}=88.0\right.$ pre-departure versus $\mathrm{a}^{-}=89.2$ on follow-up; $\mathrm{p}=$ .245). A similar observation can be made of reversal $\left(^{-}=3.58\right.$ pre departure versus 3.60 on follow-up; $\mathrm{p}=.421$ ).

Table 3. Pre/Follow-up IDI Results

\begin{tabular}{|l|l|l|l|l|l|l|l|}
\hline \multicolumn{7}{|l|}{ Paired One-tailed t-tests of Pre-test vs. Follow-up Results } \\
\hline & Pre-test Results & \multicolumn{4}{l|}{ Follow-up Results } & \\
\hline IDI scales & Ave. & Range & S.D. & Ave. & Range & S.D. $^{*}$ & p-value \\
\hline $\begin{array}{l}\text { Overall } \\
\text { Development }\end{array}$ & 88.0 & $58-126$ & 14.2 & 89.2 & $59-132$ & 14.51 & 0.245 \\
\hline Defense/Denial & 4.07 & $2.8-5.0$ & 0.55 & 3.98 & $2.8-5.0$ & 0.52 & 0.128 \\
\hline Reversal & 3.58 & $2.1-5.0$ & 0.61 & 3.60 & $2.1-5.0$ & 0.65 & 0.421 \\
\hline Minimization & 2.53 & $1.1-4.0$ & 0.6 & 2.61 & $1.1-4.3$ & 0.65 & 0.174 \\
\hline
\end{tabular}

As illustrated by Table 4, gender differences are observed in both pre- and post- IDI measurements therefore supporting Hypothesis 5. Females demonstrate significantly higher overall cross-cultural development prior to departure $\left({ }^{-}=90.5\right)$ than do their male counterparts $\left({ }^{-}=83.4 ; \mathrm{p}=.003\right)$. It appears that the primary contributing factor for the difference in the overall score is grounded in the area of defense and denial. Females scored $\left(^{-}=4.2\right)$ significantly better than males $\left({ }^{-}=3.82\right)$ at both pre-departure and at the conclusion of the study abroad experience $(\mathrm{p}=.001)$. 
Table 4. Gender Differences IDI

\begin{tabular}{|c|c|c|c|c|c|c|c|}
\hline IDI Factors & & $\begin{array}{l}\text { Pre- } \\
\text { test }\end{array}$ & $\begin{array}{l}\text { Female } \\
\text { vs Male }\end{array}$ & $\begin{array}{l}\text { Post- } \\
\text { test }\end{array}$ & $\begin{array}{l}\text { Female } \\
\text { vs Male }\end{array}$ & $\begin{array}{l}\text { Follow- } \\
\text { up }\end{array}$ & $\begin{array}{l}\text { Female } \\
\text { vs Male }\end{array}$ \\
\hline $\begin{array}{r}\text { Overall } \\
\text { Development } \\
\text { Female }\end{array}$ & 81 & 90.5 & \multirow[t]{2}{*}{0.006} & 94.4 & \multirow[t]{2}{*}{0.130} & 90.0 & \multirow[t]{2}{*}{0.452} \\
\hline Male & 45 & 83.4 & & 90.4 & & 87.8 & \\
\hline $\begin{array}{r}\text { DD Scale } \\
\text { Female }\end{array}$ & 81 & 4.2 & \multirow{2}{*}{0.000} & 4.22 & \multirow{2}{*}{0.001} & 4.04 & \multirow{2}{*}{0.134} \\
\hline Male & 46 & 3.82 & & 3.89 & & 3.89 & \\
\hline $\begin{array}{c}\text { Reversal } \\
\text { Female }\end{array}$ & 81 & 3.61 & \multirow{2}{*}{0.430} & 3.81 & \multirow{2}{*}{0.616} & 3.58 & \multirow{2}{*}{0.648} \\
\hline Male & 46 & 3.52 & & 3.87 & & 3.63 & \\
\hline $\begin{array}{r}\text { Minimization } \\
\text { Female }\end{array}$ & 81 & 2.59 & \multirow{2}{*}{0.115} & 2.62 & \multirow{2}{*}{0.351} & 2.63 & \multirow{2}{*}{0.628} \\
\hline Male & 45 & 2.42 & & 2.5 & & 2.57 & \\
\hline
\end{tabular}

At the time of the follow-up measurement, however, the differences between males and females have disappeared for both the overall development $\left(^{-}=\right.$ 90.0 females vs. 87.8 males; $\mathrm{p}=.294)$ and defensive tendencies $\left(^{-}=4.04\right.$ females vs. 3.89 males). This finding gives us pause when passing judgment on Hypothesis 6 or the proposition that gender moderates cross-cultural sensitivity between the end of the study abroad experience and follow-up measurement four-months after returning home. Strictly speaking, a nonsignificant finding is neither supportive nor the basis for rejection for any hypothesis. However, if you examine Table 5 you will find that although females did not improve pre- vs. post-measurement on the DD Scale they did experience a significant decline on DD Scale, on follow-up such that a significant difference is exhibited between both the post/follow-up and pre/ follow-up scores. Men did not exhibit any meaningful change in their DD scores over the same period. As a consequence, we are making the more conservative judgment that we have partial support for Hypothesis 6 and let the reader draw their own conclusions from the data. 
Table 5. Gender Related Differences as a Developmental Response to Study Abroad

\begin{tabular}{|r|l|l|l|l|l|l|l|}
\hline IDI Factors & & $\begin{array}{l}\text { Pre- } \\
\text { test }\end{array}$ & $\begin{array}{l}\text { Post- } \\
\text { test }\end{array}$ & $\begin{array}{l}\text { Follow- } \\
\text { up }\end{array}$ & $\begin{array}{l}\text { Pre vs } \\
\text { Post- } \\
\text { test }\end{array}$ & $\begin{array}{l}\text { Post vs } \\
\text { Follow- } \\
\text { up }\end{array}$ & $\begin{array}{l}\text { Pre vs } \\
\text { Follow- } \\
\text { up }\end{array}$ \\
\hline $\begin{array}{r}\text { Overall } \\
\text { Development }\end{array}$ & $\mathrm{n}$ & Mean & Mean & Mean & P value & P value & P value \\
\hline Female & 77 & 90.3 & 94.6 & 90.0 & 0.003 & 0.000 & 0.621 \\
\hline Male & 40 & 83.4 & 90.4 & 87.7 & 0.000 & 0.090 & 0.036 \\
\hline Memale & 77 & 4.2 & 4.23 & 4.04 & 0.518 & 0.000 & 0.007 \\
\hline Male & 40 & 3.82 & 3.89 & 3.88 & 0.343 & 1.000 & 0.492 \\
\hline Female & 77 & 3.6 & 3.82 & 3.58 & 0.000 & 0.000 & 0.481 \\
\hline Male & 40 & 3.52 & 3.87 & 3.64 & 0.001 & 0.002 & 0.308 \\
\hline Meversale & & & & & & & \\
\hline Male & 40 & 2.42 & 2.48 & 2.56 & 0.624 & 0.528 & 0.589 \\
\hline
\end{tabular}

\section{Summary of Findings}

In summary we find support for hypothesis 1 through 5 and qualified support for hypothesis 6 . For the convenience of the reader, the results for each hypothesis are summarized below: 
Table 6. Summary of Findings

\begin{tabular}{|c|c|}
\hline $\begin{array}{l}\mathbf{H}_{\mathbf{1}} \text { : A semester long, faculty-led study abroad program in a } \\
\text { native language environment will have a positive impact on the } \\
\text { development of cross-cultural sensitivity as measured at the } \\
\text { conclusion of the semester. }\end{array}$ & Supported \\
\hline $\begin{array}{l}\mathrm{H}_{2}: \text { Four months after returning home from a semester long study } \\
\text { abroad experience overall cross-cultural development will decline as } \\
\text { measured by the IDI. }\end{array}$ & Supported \\
\hline $\begin{array}{l}\mathbf{H}_{3} \text { : A decline will occur on the IDI Reversal Scale four-months after } \\
\text { returning home from a study abroad experience. }\end{array}$ & Supported \\
\hline $\begin{array}{l}\mathbf{H}_{4} \text { : No net improvement will occur in overall cross-cultural } \\
\text { development from pre-departure to a four-months after returning } \\
\text { home from their study abroad experience. }\end{array}$ & Supported \\
\hline $\begin{array}{l}\mathbf{H}_{5}: \text { Gender moderates the impact of study abroad on the } \\
\text { development of cross-cultural sensitivity as measured at the } \\
\text { beginning and the end of the SA experience. }\end{array}$ & Supported \\
\hline $\begin{array}{l}\mathbf{H}_{\mathbf{6}} \text { : Gender moderates the impact of study abroad on the } \\
\text { development of cross-cultural sensitivity between the end of the SA } \\
\text { experience and on follow-up four months after returning home. }\end{array}$ & Qualified Support \\
\hline
\end{tabular}

Figure 1. Overall IDI Development Pre, Post and Follow-up

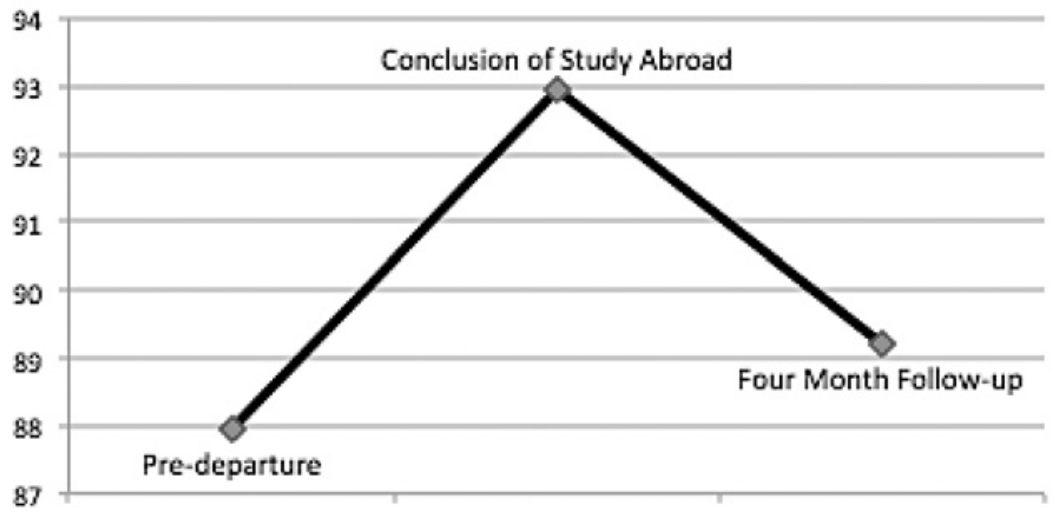




\section{Research Limitations}

We want to acknowledge, of course, several research limitations. The length of time between the end of the study abroad experience and the follow-up measure is only four months long. The study took place in a single location (London), over a fixed period of time (Fall semester), and focused exclusively on undergraduate business students studying in a faculty directed cohort model. Although a sample size of 139 students certainly supports the analysis conducted in this study, a larger and more diverse sample will add to the robustness and level of precision of future studies in addition to facilitating longer-term follow-up studies.

The students in the current study were selected to participate through a competitive selection process and therefore may not be representative of students in general that study abroad. There is also the question of whether students that decide to study abroad are somehow systematically different than students that do not study abroad. Finally, the current study does not use a control group.

\section{Discussion}

The findings of the current study add to the growing body of knowledge that study abroad has a positive impact on the development of cross-cultural sensitivity as measured at the conclusion of the study abroad experience. Overall development improved as did group reversal scores. It is disappointing, however, that our study finds again that students do not progress beyond the stage of minimization as a consequence of their study abroad. In other words, most students returning from study abroad continue to have a mono-cultural view of the world. Further research into the causes and potential treatment of this lack of progress is therefore encouraged. In other words "when does significant improvement become educationally meaningful?"

Our research continues to support the proposition that gender is a moderator of the study abroad experience with differences being observed both at the beginning and at the conclusion of the study abroad experience. It is, however, noteworthy that women will begin the experience scoring higher on cross-cultural sensitivity but on follow-up men will have closed the gap.

The principle contribution of this research is finding evidence to support the proposition that students do experience cross-cultural regression after returning home from a study abroad experience as illustrated in Figure 1. As with the previous exploratory study, reversal is the dominant reason for the observed regression in the overall development from the post-test to the followup measures. You may recall that reversal is characteristic of polarization and therefore represents a mindset where the student substitutes "we are better than 
..." for "they are better than ..." In both cases the worldview is characterized
by "us" vs. "them."

We also believe that this finding is supported by anecdotal observations of the fervor with which students express their desire to return to their study abroad location and/or engage in further international travel. While this desire for further international experiences may appear attractive and may even be encouraged by study abroad enthusiasts, if the underlying cause of the interest is polarization or reversal, then we have what is known in the sciences as a false positive indicator of student achievement.

We believe that the most plausible explanation for observing developmental regression in students after they return home is that the students are experiencing a classic boomerang effect. It is hypothesized that for many students study abroad is a time of idealized or romanticized freedom and when they are again confronted with the realities of home they predictably experience the boomerang effect; measured effectively by the IDI as reversal. This suggests that study abroad programs should provide "re-entry" support to help students reflect and gain further perspective on the unique "set of freedoms" that they experienced while studying abroad (Brehm, 1966; Brehm \& Brehm, 1981; Burgoon et al., 2002).

To further test our hypothesis about the boomerang effect, we speculate that a student's perception of their intercultural competence (PSDS gap), or the difference between the perceived development score and actual development score, will decline as a result of the study abroad experience but will then increase on follow-up. As a general rule, the Perceived Scale shows that people believe that they possess a higher level of cross-cultural sophistication than what the IDI actually measures. This positive halo effect is a very common finding in the self-judgment measures used in social psychology. To our knowledge we are the first to use the PSDS Scale to test a cross-cultural hypothesis. Also, given that our speculation was generated after the data was collected we used the more conservative post hoc Scheffé procedure to test our hypothesis.

The rationale for testing the PSDS Scale as an indirect measure of the boomerang effect is based on studies of psychological reactance that have reported a negative relationship between self-awareness of the effect and a reduction of the effect. In other words, the more self-aware you are of the possibility of the effect, the less likely you are to experience the effect. Hence we expect to find further support for the cross-cultural boomerang effect if there is an improvement in self-adjustment between the pre- and postmeasurements as reflected in a small post-PSDS Scale score and a decline in self-judgment between the post and follow-up PSDS Scale. To reiterate, the larger the PSDS score the less accurate a person is in judging his or her own cultural development. 
When we look at the gap between the students' perceived score and their actual development score at the end of the study abroad experience, we find as predicted a significant decline in the PSDS Scale $(p=.000)$. In other words, students have a more accurate view of their own cross-cultural development and this matches the improvement that we see in the students overall development. On follow-up also, as predicted, we find a significant increase in the PSDS Scale gap when compared to the conclusion of the study abroad experience $(\mathrm{p}=.000)$. When comparing the pre-departure with the follow-up PSDS Scale $(\mathrm{p}=.487)$ we find no significant change similar to what we observed with the Reversal and Overall Development Scales. Using the Scheffé post hoc hypothesis test we find the predicted changes in the PSDS scores are approaching significance $(\mathrm{p}=.055)$. We recognize, of course, that this post hoc test does not prove that the boomerang effect is the root cause of the observed reversal, but it does lend credibility to the possibility of the effect. And the good news is, if we have accurately diagnosed the cause of the regressive behavior, then recommendations for re-entry treatment are relatively straightforward and are easily subject to further empirical testing.

There is an extensive literature on repatriation and it may be time for us to rethink the implications of this literature for students returning home from study abroad experiences. Although students have an expectation of change and some basic understanding of a need for adaptation when traveling abroad, our experience suggests that students are often not equally well prepared for the repatriation process - thinking, as they do, that they are "just going home". The inevitable tension that this creates when they discover that home hasn't changed but they have, naturally causes them to long for the good ol' days of being abroad. The boomerang effect then manifests itself in the form of reversal where the student romanticizes the study abroad location as being culturally superior to their native culture. In the past, we may not have taken much notice of this in part due to the structural disconnect that can naturally occur when the student returns home and, as such, they have effectively "graduated" from our responsibility. When and where there is contact with our former study abroad students, they are likely to tell us what we want to hear, "I really loved the study abroad experience" and "I want to travel more" hence disguising a new developmental challenge.

As also noted in our results section there was only qualified support for the role that gender played in the development of students after returning home. As relates to the specific issue of the boomerang effect we see no difference between men and women in terms of their scoring on the Reversal Scale. 


\section{Summary and Conclusions}

Our study reaffirms the general finding that study abroad has a positive impact on cross-cultural development as measured at the conclusion of the study abroad experience. Our findings related to the boomerang effect should both encourage and challenge those with an interest in study abroad. Study abroad programs should take note that without further intervention, the positive gains achieved while abroad may be lost, at least temporarily, after returning home. Future research will also want to assess the duration of the boomerang effect. It is possible, given more time for reflection and experience, that students will grow out of the initial regression they experience when returning home. For now, however, this possibility remains an open empirical question.

To the extent that we are correct in identifying the boomerang effect as the cause of the regressive behavior described in this study, then we recommend re-entry strategies that will help guide the students to reflect on the experience within the context of all of their other life-experiences. We also acknowledge that this is a single study and that further research is needed to either corroborate or disconfirm our findings.

\section{References}

AACSB: Association to Advance Collegiate Schools of Business (2012). International Eligibility Procedures and Accreditation Standards for Business Accreditation, Specifically standards 15, $16 \& 18-20$. Retrieved February 2012, http://www.aacsb.edu/accreditation/ standards-busn-jan2012.pdf

Anderson, P, L. Lawton, R.J. Rexeisen and A. Hubbard, (2006). "ShortTerm Study Abroad and Intercultural Development: A Pilot Study" International Journal of Intercultural Relations, Vol 30, No 4.

Anderson, P. and L. Lawton (2011). "Intercultural Development: Study Abroad VS. On-Campus Study," Frontiers: The Interdisciplinary Journal of Study Abroad, XXI.

Bennett, M. J. (1986). "Toward ethnorelativism: A developmental model of intercultural sensitivity," In R. M. Paige (Ed.), Cross-cultural orientation: New conceptualizations and applications (pp. 21-70). New York:

University Press of America.

Bennett, M.J. (1993). "Toward Ethnorelativism: A Developmental Model of Intercultural Sensitivity," In R.M. Paige (Ed.) Education for the Intercultural Experience. 21-71. Yarmouth, ME: Intercultural Press. Bennett, M.J. (2004). “Becoming interculturally competent,” In J. Wurzel (Ed.), Toward multiculturalism: A reader in multicultural education. (2nd 
ed., pp. 62-77).

Braskamp, L. A., Braskamp, D. C., \& Merrill, K. C. (2009). “Assessing progress in global learning and development of students with educational abroad experiences," Frontiers: The Interdisciplinary Journal of Study Abroad, Vol. XVIII, $101-118$.

Brehm. J. (1966). A theory of psychological reactance. New York: Academic Press.

Brehm, S. S., \& Brehm, J. W. (1981). Psychological reactance: A theory of freedom and control. San Diego, CA: Academic Press.

Burgoon, M., Alvaro, E., Grandpre, J., \& Voloudakis, M. (2002). Revisiting the theory of psychological reactance: Communicating threats to attitudinal freedom. In J. Dillard \& M. Pfau (Eds.), The persuasion handbook: Developments in theory and practice (pp. 175-194). Thousand Oaks: CA, Sage.

Davis, S. and Finney, S. (2006). A Factor analytic study of the cross-cultural adaptability inventory. Educational and Psychological Measurement, 66(2), 318-330.

de Witt, Hans (2010). Internationalisation of Higher Education in Europe and its Assessment, Trends and Issues, NVAO: Accreditation Organization of the Netherlands and Flanders, pp. 12 - 16.

Expanding Study Abroad Capacity at U.S. Colleges and Universities, (2009), Meeting America's Global Education Challenge, IIE Study Abroad White Paper Series: Issue Number 6 (http://www.iie.org/en/ Research-and-Publications/Research-Projects/ /media/Files/Corporate/ Membership/StudyAbroad_WhitePaper6.ashx)

Franklin, Kimberly (2011). "Long-term Career Impact and Professional Applicability of the Study Abroad Experience," Frontiers: The Interdisciplinary Journal of Study Abroad, XIX.

Hammer, M.R. (2007). The Intercultural Development Inventory Manual (v.3). Ocean Pines, MD: IDI, LLC.

Hammer, M.R. (2008). "The Intercultural Development Inventory (IDI): An Approach for assessing and building intercultural competence.," In M.A. Moodian (Ed.), Contemporary leadership and intercultural competence: Understanding and utilizing cultural diversity to build successful organizations. Thousand Oaks, CA: Sage.

Hammer, M.R. (2012). Developing Intercultural Competence. (Last retrieved, March 2012, http://www.idiinventory.com/ )

Hammer, M.R. and Bennett, M.J. (2002). The Intercultural Development Inventory (IDI) Manual. Portland, OR: Intercultural Communication Institute. 
Hammer, M. R., Bennett, M. J., \& Wiseman, R. (2003). "Measuring intercultural sensitivity: The Intercultural Development Inventory," International Journal of Intercultural Relations, 27, 421-443.

Higher Learning Commission. (2012). Overview of accreditation, standards, 4c, p. 6. (http://www.ncahlc.org/Information-for-Institutions/criteriafor-accreditation.html )

Kelley, C., \& Meyers, J. (1995). CCAI Cross Cultural Adaptability Inventory Manual. Minneapolis, MN: National Computer Systems, Inc.

Medina-López-Portillo, A. (2004). "Intercultural learning assessment: The link between program duration and the development of intercultural sensitivity," Frontiers: The Interdisciplinary Journal of Study Abroad, 10, 179-199.

Niu, R \& G. Cooper (2010). “Assessing International Learning: A Mixed Methodological Approach to Assessing Curricular and Extracurricular International Experiences," The Journal of General Education, Vol. 59, No. 3.

Norris, E. \& J. Gillespie (2008). "How Study Abroad Shapes Global Careers: Evidence From the United States," Journal of Studies in International Education, pp. 382 - 397.

Paige, R.M., Jacobs-Cassuto, M., Yershova, Y. and DeJaeghere (2003) "Assessing Intercultural Sensitivity: An Empirical Analysis of the Hammer and Bennett Intercultural Development Inventory," International Journal of Intercultural Relations, 27 (4), 467-486. Paige, R. M., Cohen, A. D. and Shively, R. L. (2004). "Assessing the impact of a strategies-based curriculum on language and culture learning abroad," Frontiers: The Interdisciplinary Journal of Study Abroad, Volume X, Fall, 253-276.

Pedersen, P.J. (2010). "Assessing intercultural effectiveness outcomes in a year-long studyabroad program," International Journal of Intercultural Relations, (34), pp. 70-80.

Rexeisen, R. J., \& Al-Khatib J. A. (2009). "Assurance of learning and study abroad: A case study," Journal of Teaching in International Business, 20(3), 192-07. doi 10.1080/08975930903099077

Savicki,V., Downing-Burnette, R., Heller, L., Binder, F. \& Suntinger, W. (2004). Contrasts, changes, and correlates in actual and potential intercultural adjustment. International Journal of Intercultural Relations, 28, 311-329.

Shaheen, S. (2004). The Effect of Pre-Departure Preparation on Student Intercultural Development during Study Abroad Programs, Unpublished Doctoral dissertation, The Ohio State University (http:// 
etd.ohiolink.edu/view.cgi?acc_num=osu1091481152 )

Shealy, C. N. (2005). "Justifying the Justification Hypothesis: ScientificHumanism, Equilintegration (EI) Theory, and the Beliefs, Events, and Values Inventory (BEVI)," [Special Series]. Journal of Clinical Psychology, 61 (1), 81-106.

Shimp, T. A. and Sharma, S. (1987). "Consumer ethnocentrism: construction and validation of the CETSCALE," Journal of Marketing Research, 24, August, 280-289.

U.S. Department of Education, National Center for Education Statistics, (2010). The condition of Education 2010, pp. $118 \& 294$.

Vande Berg, M., Connor-Linton, J. and R.M. Paige (2009). "The Georgetown Consortium Project: Interventions for Student Learning Abroad," Frontiers: The Interdisciplinary Journal of Study Abroad, Vol. XVIII, pp. 1 - 75 . 
